\title{
A Note on Terminology
}

Writing about China in English presents a number of challenges regarding the presentation of Chinese names and terms. Since the 1980s, the pinyin system of Romanisation developed in mainland China during the 1950s has been used in the West, and this is also the system used in this book. The only exception is when scholars are known in English by names that use other forms of Romanisation, such as You-tien Hsing, or when older films are known by titles not based on pinyin, such as Antonioni's Chung kuo.

Chinese names have been rendered in the Chinese style, with family names appearing first. The only exception is Chinese authors who have published books and articles in English using the English-language name order, such as You-tien Hsing, Yingchi Chu or Ying Qian. In these instances the names are cited as published.

Throughout this book I have used the term 'party-state' to refer to the governmental authority that has ruled over China since 1949. In theory the Chinese Communist Party (CCP) and the Chinese state are separate entities, and parallel party and state structures exist at all levels of authority. For example, the State Council is theoretically the highest body of governance in China, while the Politburo is the body that governs the Communist Party. In reality the Party penetrates and dominates the state at every level, and state organs invariably reflect and carry out the policies and orders of the Party. Thus, the Politburo Standing Committee is in practice the body that governs China. For this reason 'party-state' is the most appropriate description of China's governance structure.

The final point of clarification relates to the use of the term 'China'. The political entity of the People's Republic of China today encompasses the Special Administrative Region of Hong Kong, but the SAR continues to maintain its own currency, education system, judiciary and laws. Most importantly, the censorship rules and processes designed to shape and guide public culture in the mainland do not apply in Hong Kong, even if their influence has been increasingly felt in recent years. Additionally, the 'province' of Taiwan continues to operate essentially as a separate state (officially the Republic of China), despite Beijing claiming jurisdiction over the island. Thus, for the purposes of this study, when conditions are described in 'China', this is taken to refer exclusively to the 


\section{xii Independent Chinese Documentary}

mainland controlled by the Chinese Communist Party, excluding both Hong Kong and Taiwan.

For reference purposes, a glossary of Chinese terms used in the text appears at the end of this book, and a complete list of the Chinese films and filmmakers discussed appears in the filmography in both pinyin and Chinese characters. 